\title{
QUEEN'S
UNIVERSITY
BELFAST
}

\section{Family-focused practice with EASE: A practice framework for strengthening recovery when parents have mental illness.}

Foster, K., Goodyear, M., Grant, A., Weimand, B., \& Nicholson, J. (2019). Family-focused practice with EASE: A practice framework for strengthening recovery when parents have mental illness. International Journal of Mental Health Nursing, 28(1), 351-360. https://doi.org/10.1111/inm.12535

\section{Published in:}

International Journal of Mental Health Nursing

\section{Document Version:}

Peer reviewed version

Queen's University Belfast - Research Portal:

Link to publication record in Queen's University Belfast Research Portal

\section{Publisher rights}

Copyright 2019 Wiley. This work is made available online in accordance with the publisher's policies. Please refer to any applicable terms of use of the publisher.

\section{General rights}

Copyright for the publications made accessible via the Queen's University Belfast Research Portal is retained by the author(s) and / or other copyright owners and it is a condition of accessing these publications that users recognise and abide by the legal requirements associated with these rights.

Take down policy

The Research Portal is Queen's institutional repository that provides access to Queen's research output. Every effort has been made to ensure that content in the Research Portal does not infringe any person's rights, or applicable UK laws. If you discover content in the Research Portal that you believe breaches copyright or violates any law, please contact openaccess@qub.ac.uk. 


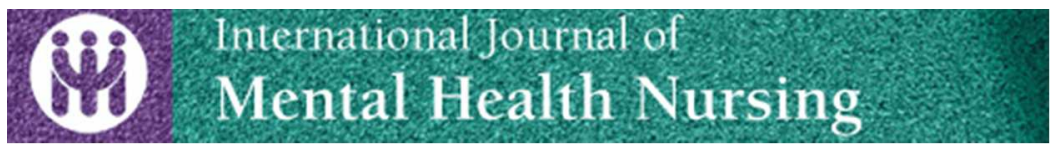

\section{Family-focused practice with EASE: A practice framework for strengthening recovery when mental health consumers are parents}

\begin{tabular}{|r|l|}
\hline Journal: & International Journal of Mental Health Nursing \\
\hline Manuscript ID & Draft \\
\hline Kanuscript Type: & Discursive Papers \\
\hline Keywords: & recovery, parenting, family, family-focused practice, children \\
\hline & $\begin{array}{l}\text { Family and significant others are important relationships in peoples' lives } \\
\text { and provide essential psychosocial support to mental health consumers, } \\
\text { many of whom are or will become parents. Yet individualistic approaches to } \\
\text { practice continue to dominate mental health service provision and there is } \\
\text { a need for more inclusive approaches that address family relationships and } \\
\text { needs. Relational recovery is an emergent approach that views people as } \\
\text { inter-dependent relational beings. Recovery from mental illness is } \\
\text { understood to occur as a social process with relationships affecting all } \\
\text { aspects of recovery. Nurses and other clinicians play key roles in } \\
\text { supporting the recovery of parents with mental illness and it is well- } \\
\text { established that family-focused practice is necessary; however there are } \\
\text { barriers to making it happen. There is a critical need for practice } \\
\text { frameworks that provide guidance on clinician-initiated family-focused } \\
\text { interactions. This paper describes an evidence-and practice-informed } \\
\text { practice framework - EASE (Engage, Assess, Support, Educate) - of } \\
\text { essential family-focused practices through brief interactions that all } \\
\text { clinicians can have with parent/consumers. The central aim is to } \\
\text { strengthen clinicians' capacity to address key psychosocial needs of } \\
\text { parents and to strengthen relational recovery in families where parents } \\
\text { have mental illness. EASE builds on the existing therapeutic relationship } \\
\text { between clinician and parent/consumer and draws on clinicians' knowledge } \\
\text { about consumers' family contexts. EASE practice components are defined } \\
\text { and illustrated with case exemplars, providing a practical guide for working } \\
\text { with parents in the context of their family in adult mental health settings } \\
\text { and other contexts including child welfare and primary health care. }\end{array}$ \\
\hline Abstractions \\
\hline
\end{tabular}




\title{
TITLE: Family-focused practice with EASE: A practice framework for strengthening recovery when mental health consumers are parents.
}

\begin{abstract}
Family and significant others are important relationships in peoples' lives and provide essential psychosocial support to mental health consumers, many of whom are or will become parents. Yet individualistic approaches to practice continue to dominate mental health service provision and there is a need for more inclusive approaches that address family relationships and needs. Relational recovery is an emergent approach that views people as inter-dependent relational beings. Recovery from mental illness is understood to occur as a social process with relationships affecting all aspects of recovery. Nurses and other clinicians play key roles in supporting the recovery of parents with mental illness and it is well-established that familyfocused practice is necessary; however there are barriers to making it happen. There is a critical need for practice frameworks that provide guidance on clinician-initiated family-focused interactions. This paper describes an evidence-and practice-informed practice framework - EASE (Engage, Assess, Support, Educate) - of essential family-focused practices through brief interactions that all clinicians can have with parent/consumers. The central aim is to strengthen clinicians' capacity to address key psychosocial needs of parents and to strengthen relational recovery in families where parents have mental illness. EASE builds on the existing therapeutic relationship between clinician and parent/consumer and draws on clinicians' knowledge about consumers' family contexts. EASE practice components are defined and illustrated with case exemplars, providing a practical guide for working with parents in the context of their family in adult mental health settings and other contexts including child welfare and primary health care.
\end{abstract}

\section{KEYWORDS}

Recovery, parenting, family, mental illness, family-focused practice, children 


\section{INTRODUCTION AND AIM}

This paper provides a framework for essential family-focused practices (EASE: Engage, Assess, Support, Educate) for clinicians to support parents with mental illness in the context of their family. The framework is underpinned by relational recovery as the parent/consumer's recovery is considered within the context of their relationships, including the relationship between clinician and parent/consumer. The central aim is to strengthen nurses' and other clinicians' capacity to address key psychosocial needs of parents and to strengthen relational recovery in families where parents have mental illness. The EASE framework is a theory and evidenceinformed family practice approach to relational recovery within current healthcare provision. The EASE practice components are defined and illustrated with case exemplars that operationalize the framework within adult service settings. Potential applications and outcomes of using EASE are also described. The framework is intended as a practical guide for working with parents and families in inpatient and community mental health settings, and may also be relevant for clinicians in a range of contexts including child welfare and primary health care.

\section{BACKGROUND}

\section{Working with families in mental health}

Family members and significant others are important relational connections in peoples' lives. The presence or absence of supportive relationships is known to influence mental, emotional, social, and physical health and wellbeing (Umberson \& Montez 2010). In the context of mental health, family members and carers provide essential physical and psychosocial support to people with mental ill-health, many of whom are or will become parents (Naughton et al. 2017).

'Family' has been variously defined in the literature, but includes individuals with mental illness 
and their partners, children, extended family members such as grandparents, and close personal relationships. Following Osher and Osher (2002), in this paper 'family' is understood to be defined by its members and is not limited to a nuclear family structure.

In Australia and elsewhere the individualistic medical model has impeded a deeper understanding of the psychosocial family context within which people with mental illness live, with missed opportunities for enhancing individual and family or relational recovery (Nicholson et al. 2015; Price-Robertson et al. 2016; Reupert et al. 2015). Due to this, there are mounting calls for more inclusive approaches that consider adults in the context of their family life, and recognize child, parent, and family relationships and the needs of parents (Foster \& Isobel 2017; Foster et al. 2012; Goodyear et al. 2015; Price-Robertson et al. 2016; Weimand 2013a). Relational recovery is an emergent approach in mental healthcare that views people as interdependent relational beings, and relationships as being multi-directional and both positive and negative. From a relational standpoint recovery from mental illness is understood to occur in the context of relationships as a social process where relationships affect all aspects of recovery (Price-Robertson et al. 2016). From this perspective, family and family relationships are the context for recovery for people with mental illness who are parents.

\begin{abstract}
Nurses and other clinicians play key roles in supporting the recovery of parents with mental illness through family-focused practice (Foster et al. 2012; Foster et al. 2016; Grant \& Reupert 2016; Korhonen et al. 2010; Reupert et al. 2015). Clinicians can find it challenging, however, to support parents in the context of their family due to a range of barriers including lack of relevant practice models and training (Goodyear et al. 2017; Weimand 2013b). There is a substantial
\end{abstract}


body of evidence that while nurses and other clinicians recognize the importance of addressing consumers' needs as a parent and family member, they can struggle with a lack of confidence, lack of time, lack of role clarity, and lack of clinical skills and knowledge to engage readily with parent/consumers and their children about mental illness (Foster \& Isobel 2017; Goodyear et al. 2015; Maybery et al. 2014). There is a critical need for practice frameworks that privilege clinicians' relationships with consumers who are parents; that promote relationships and strengths within families; and that build parent self-efficacy and capacity to understand and address their mental illness in the context of their children and family.

\section{Needs of parents with mental illness}

Parental mental illness is a major public health issue internationally. Two thirds of American adults living with mental illness are parents (Nicholson et al. 2015). In Australia, estimates indicate that $23 \%$ of all people with mental illness are parents of dependent children (Maybery et al. 2009), and that over $50 \%$ of women and $25 \%$ of men with serious mental illness are parents (Campbell et al. 2012). In the UK, two million children are understood to live in households where at least one parent had a mental health problem (Parrott et al. 2008); while in Australia there are $\sim 1,082,403$ children living in 577,507 families with a parent with mental illness (Maybery et al. 2015). Mental illness is an intergenerational issue, and children of parents with mental illness have a substantially increased risk of developing mental illness (up to 55\%) (Rasic et al. 2014) due to a range of genetic, environmental, and psychosocial factors (Foster et al. 2012). 
Parenting is a key role in many peoples' lives and parents often seek guidance to address their children's needs, particularly in relation to any potential impacts of their illness on their children (Hine et al. 2018; Nicholson 2014). Parents with mental illness have the same parenting issues as others parents but may experience greater challenges due to poverty and social isolation (Hine et al. 2018), stigma and discrimination (Foster et al. 2017), and lack of targeted support for parenting when they are unwell (Campbell et al. 2012; Naughton et al. 2017). Parents report the need for emotional support and mental illness information and education from professionals for themselves and their children (Maybery et al. 2005), practical support such as childcare (Rampou et al. 2015), and assistance with everyday parenting stressors and challenges (Grant et al. 2018; Montgomery et al. 2011). Parents may seem difficult to engage by mental health services regarding family issues due to a range of factors including parents' concerns they will be considered unfit to parent and their children will be removed from their care, custody issues, and previous negative experiences with clinicians in regard to parenting issues (Goodyear et al. 2015; Nicholson 2014). Evidence indicates, however, that when parents are engaged with health services they are not necessarily identified as parents (Foster et al. 2017; Isobel et al. 2015) nor asked by clinicians about their children or about their family status and relationships (Goodyear et al. 2015).

\section{Family-focused practice in mental health}

Family-focused practice (FFP) is the provision of psychosocial support to the family as a unit, including the person with mental illness, their child/ren, partner and other family members (Foster et al. 2012). This approach acknowledges the strengths as well as vulnerabilities of individual family members and the family as a whole, and aims to support family choices and 
collaboration in treatment (Foster et al. 2016). Timely provision of FFP can help reduce subjective and objective burden for family members, improve mental health literacy, support family relationships and children's wellbeing, and be preventative for intergenerational mental illness (Foster et al. 2012). Six core elements of FFP derived from systematic review of the literature are: assessment, provision of psychoeducation, social, emotional, and practical support, family care planning and goal setting, liaison between families and services, and a coordinated system of care (Foster et al. 2016). For families where parents have mental illness, elements of particular relevance include psychoeducation for parents, children and key family members, appropriate mental health intervention for the parent, and parenting support (Marsten et al. 2016). However, it is not always feasible or necessary to perform all aspects of FFP, and familyfocused practices exist on a continuum of intensity ranging from essential or fundamental practices such as identification of parent status and checking child/ren's status, through to higher intensity practices such as family case management and family therapy (Foster et al. 2012). The EASE practice framework described in this paper sits at the essential end of the FFP continuum and EASE is a brief, low intensity intervention of fundamental family-focused practices upon which more intensive practices can build and extend, for example Let's Talk (Solantaus et al. 2009), the Family Model approach (Falkov 2015), and Family Options (Nicholson et al. 2016).

As the largest professional group in mental healthcare in many countries (Foster et al. 2012), nurses are in a unique position to engage in FFP (Grant \& Reupert 2016; Maybery et al. 2014). They are often the first point of contact for parents receiving treatment in adult mental health services, and are "among the few groups of health professionals who have direct, frequent, and sustained contact with consumers and families" (Foster et al. 2012, p. 6). This allows them to 
form relationships with parents at a time when they are likely to be experiencing difficulties in parenting due to the acute nature of their illness (Foster et al. 2012), which means nurses are also uniquely positioned to evaluate children's situations and prevent problems arising (Korhonen et al. 2010). Although there is growing evidence that some mental health nurses engage in FFP (Grant \& Reupert 2016; Korhonen et al. 2010; Tungpunkom et al. 2017) available data in Australia and elsewhere indicate that most nurses are not particularly family-focused (Grant et al. 2015; Maybery et al. 2014; Maybery et al. 2016). Grant (2016), for instance, found significant differences between the extent of nurses' FFP in acute inpatient units and community mental health services in Ireland, with those in community settings more family focused. In Australia and Northern Ireland, clear differences have been found between professional groups, with social workers engaged the most in FFP, while nurses (Maybery et al. 2014) and psychiatrists (Grant et al. 2018) performed the least.

Evidence indicates there are service-related, clinician-related, and family-related barriers to provision of mental health family-focused care. As the medical model continues to substantially underpin the provision of mental health treatment and focuses on individuals and not families, mental health clinicians may not be supported by their organizations to engage in FFP (Nicholson et al. 2015). Inadequate time, lack of structure and resources are further barriers to working in a family-focused way (Grant et al. 2015), as are staff shortages, high workloads, and high staff turnover; particularly in acute inpatient settings (Grant et al. 2018). Barriers also stem from clinicians' attitudes, knowledge, and skill set on child and family support needs (Foster \& Isobel 2017; Grant et al. 2015), and from parents, children and adult family members who may be reluctant or not available to discuss family issues (Grant \& Reupert 2016; Maybery et al. 
2015). A brief, low-intensity FFP approach as part of routine practice, focused on essential family-focused practices, is one way to address identified barriers to practice and to support parents with mental illness in their parenting role.

\section{Supporting recovery through family-focused practices}

While much of the literature on parents with mental illness has focused on meeting their needs, it is important to recognize that parents are in mutually dependent relationships with family. Thus, family and other close relationships are multi-directional (Reupert et al. 2015). These relationships have an impact on the person with mental illness, and the individual has a reciprocal impact on children and other family members in a 'give and take' process (Reupert et al. 2015; Ward et al. 2017). Many health services, however, find it challenging to meet the needs of parents who are mental health consumers. A recent focus has been on mental health services supporting a holistic psychosocial view of recovery for a person with mental illness. This is consistent with, yet builds upon, a personal recovery approach which recognizes there can be meaningful personal change and a journey of social engagement for the person with mental illness (Tew et al. 2012). In a systematic review and synthesis, personal recovery was associated with five core foci domains: Connectedness, Hope and optimism about the future, developing a positive Identity, finding Meaning in life, and Empowerment (CHIME) (Leamy et al. 2011). A parenting role often underpins and can have a positive or negative influence on all these domains of personal recovery (Maybery et al. 2015). While parenting is not specifically highlighted in recovery-focused models of mental health care, supporting an individual as a parent can be seen to be aligned with personal recovery goals associated with supporting a person's identity and connectedness, and helping to support relational aspects of the person's life. 
In respect to recovery, family life and relationships between parents and children can provide motivation for change and hope for the future (Hine et al. 2018). Family relationships are sustained when family members can communicate about matters of importance to them, and they are heard and understood by other family members. Given the predominant focus on the individual in mental health services, the needs of family members in terms of their own need for support and information have often been overlooked (Weimand et al. 2017). Research has shown that family members may have contrasting views regarding a consumer's mental illness and treatment (Weimand 2011, 2013a). Traditionally, clinicians have often worked with consumers in a clinician/consumer dyadic conversation. However, triadic conversations, where a family member such as a child or partner is also present (Dalton 2013), can include family members' knowledge, attitudes and expectations and help the parent/consumer and family member identify and address their particular needs. In using the EASE framework with parents with mental illness, it may be important and relevant to include triadic as well as dyadic conversations that explore each family member's needs.

\section{DESIGN AND METHOD}

This paper provides a practice framework for working with parents and families where a parent has mental illness. Practice frameworks are conceptual maps for clinical practice with specific client groups which are presented in an accessible format (Connolly 2007). Such a framework provides the means by which theory, practice and research can be integrated (Connolly 2007) to support better outcomes for parents and families where parents have mental illness. The EASE framework is evidence-and practice-informed and underpinned by the conceptual framework of relational recovery (Price-Robertson et al. 2016), and by principles of implementation science 
(Fixsen et al. 2009). The framework is intended as a tool to provide clinicians with theoreticallyinformed practice logic (Connolly 2007) and a set of initial questions and actions to support fundamental family-focused practices.

The EASE framework is informed by substantial international literature in the field of families where parents have mental illness and family-focused practice, and by the authors' expert experience in the field. A structured practice framework, stemming from both the evidence base of family-focused practice and clinical experience, can help guide the mental health workforce to meet the needs of parents and their family relationships in everyday practice. From an implementation science perspective, a structured practice framework can act as an important driver to enhance worker skill and competency, and to provide organisational leadership with standards for performance development and practice measurement. These are significant structural supports required to underpin the translation of new practice into routine service delivery (Fixsen et al. 2009; Michie et al. 2009). The benefits of distilling theory and evidence into a concise practice framework to guide family-focused work in various settings and sectors can assist with translation to practice issues (Goodyear et al., 2015). Known barriers to familyfocused practice (e.g. Landeweer et al. 2017) can be addressed through clear operational definitions and practice specifications, and careful and considered development of workforce training foci and strategies (Biebel et al. 2014; Fixsen et al. 2005).

\section{EASE PRACTICE FRAMEWORK}

The EASE framework (Engage, Assess, Support, Educate) comprises essential components of FFP when working with parents with mental illness in the context of their family. EASE 
practices are at the low intensity end of the FFP continuum of practice (Foster et al. 2012) and address the fundamental needs of a parent in the context of their family as these are the foundation for more intensive intervention (Reupert \& Maybery 2014). While previous literature has identified key components of FFP (Foster et al. 2012; Foster et al. 2016; Goodyear et al. 2015), these have yet to be operationalized into a brief descriptive framework for essential practices for adults receiving mental health services. This concise family-focused practice framework provides opportunity for brief intervention with the aim of obtaining meaningful information about parent/consumers and their families and to meet the immediate needs of the parent and, as feasible, key family members including children. In inpatient settings for instance, admissions are often restricted to brief length of stays which may limit extensive relationship development with consumers and families. Admission or intake to a service does, however, provide a point of opportunity to capture information about family roles, relationships and goals, and provide brief interventions that can inform care and discharge planning.

The following describes the key principles and components of practice that are fundamental to providing family-focused care for parents with mental illness in the context of their families. The EASE framework has a set of underlying principles and specific core components to guide clinicians when working with a parent with mental illness. These practice principles and elements can be integrated into a conversation or sequence of conversations the clinician has with the parent over the course of their relationship, whether in an inpatient unit or a communitybased setting. Whether the relationship is short-term or ongoing, the premise of the EASE framework is that a conversation of any length about parenting and family can promote an impactful clinician/parent relationship and open the door to further support for the family 
including more intensive family-focused interventions. While EASE is focused on parents with mental illness, as relevant for each family situation the practices also include consumers' partners and children. Ultimately, the intent is to support positive outcomes for the parent, and their dependent children and close family members such as partners.

\section{Principles of EASE}

Key underlying principles of the EASE framework reflect aspects of an approach to practice that shape the clinician's 'stance' with the parent (Emerging Minds 2016). These include: addressing stigma and hesitancy; taking a parenting focus with an eye towards the person's roles, responsibilities and priorities as a parent; promoting resilience and recovery; understanding families' unique experiences; and reflecting on practice experiences that may remind or be similar to the clinician's own life experiences. Further, work in the U.S. drawn from an ecological model of family recovery has highlighted the importance of practice underpinnings that promote an approach that is family-centered, strengths-based, recovery-focused, and traumainformed (Nicholson et al. 2016; Nicholson et al. 2014). These principles have been translated into generic standards of practice for the adult mental health workforce (Goodyear et al. 2015). Practice standard recommendations that are relevant to EASE include obtaining essential information about consumers' status as a parent and that of their children; considering parents' strengths, resources and vulnerabilities; supporting the parenting role; and considering, as relevant, the support needs of key family members such as partners and children (Goodyear et al. 2015). 
The key principles that provide the underpinnings of the EASE practice framework are: (1) take a parent focus, that is, consider the person's status, roles, responsibilities and desires as a parent; (2) recognize a parent's strengths and resources as well as vulnerabilities; (3) acknowledge the contribution of family life experiences and relationships to a parent's recovery and the mutuality in family relationships; and (4) understand that, while many life experiences may be similar or shared, each parent and family is unique, with goals specific to their family, cultural context, and past and present circumstances. These principles are focused on identifying and building strengths, enhancing recovery, and strengthening family relationships (Goodyear et al. 2015; Reupert \& Maybery 2014; Van der Ende et al. 2016).

\section{Components of EASE}

Key components in the EASE framework are essential family-focused intervention processes (Foster et al. 2016) that can promote positive outcomes for consumers who are parents, and as relevant, their child/ren and partner. These elements do not necessarily need be addressed in a linear fashion and may have feedback loops that integrate and strengthen the approach. The EASE components and practice guidelines and examples are outlined in Table 1, and the practices are demonstrated in case examples for inpatient and community settings.

\section{Engage}

Engagement is the process of building a relationship with a parent (and family members as relevant), and building rapport and a sense of trust and collaboration. A positive therapeutic alliance is a core feature of effective clinical relationships in mental health (Thurston 2003), and is characterized by mutual partnership and consumer empowerment. A positive therapeutic 
alliance has been associated with positive healthcare experiences and outcomes for consumers (Zugai et al. 2015). When parents have mental illness, the alliance requires careful consideration by the clinician of factors that may conspire to make a parent reluctant to form a relationship and openly discuss aspects of parenting, family life and the impact of mental illness on their children. Consumers' experiences may range from never having been asked about their parenting status before, to having been quizzed about their child's family life by workers, to having been thoroughly investigated in their home by child welfare workers (Hine et al. 2018). Consequently, parents may think talking about parenting is not important, inappropriate, or even risky, if the custody of their children has ever been in question (Grant et al. 2018). This hesitancy or reluctance may have been viewed by clinicians in the past as non-compliance, avoidance or manipulation on the part of the parent.

A non-judgmental approach will promote engagement in the clinician/parent relationship (Nicholson et al. 2014; Reupert \& Maybery 2014), particularly if the clinician approaches the consumer without making assumptions about his/her capacity to parent based on their illness status. The engagement approach involves open questions exploring the consumer's parenting status and family relationships, details about their children, key values and goals in relation to parenting and their family, and building the foundations for a collaborative partnership focused on addressing the parent's (and as relevant their partner's/child's) current key needs in relation to the parent's mental illness.

\section{Assess}

Assessment here is focused on essential aspects rather than a comprehensive family assessment. Assessment involves identifying consumers as parents of dependent children and any adult 
children, and the current parent/child situation (e.g. whether parents and children are living together), whether the parent has a partner, key family relationships, and strengths and needs as a parent (Foster et al. 2016). Asking these key questions early in the working relationship with parents can support the therapeutic alliance through showing interest and concern, and encourage positive change in families (Reupert \& Maybery 2014). This does not mean the clinician must meet with each family member; they may only have contact with the consumer who is a parent to reflect on their family needs. Parents may be at different ages and life stages, with dependent children living with them or adult children with whom they have supportive or conflicted relationships. Children may provide support and caring themselves, perhaps appropriate for adult children but less so for young children.

\begin{abstract}
An understanding of family relationships and circumstances will inform family-focused discharge planning (Reupert \& Maybery 2014) and treatment planning. Respect for these relationships and alignment of a parent's goals for their parenting in relation to their recovery goals will contribute to engagement in the clinician/parent relationship and a positive therapeutic alliance - an example of the feedback loops in EASE practices. Importantly, any assessment and actions that clinicians take as a result of interactions with parents or family should be documented in the parent/consumers' case notes.
\end{abstract}

\title{
Support
}

Support includes brief practical or instrumental support such as helping organizing transport and referring parents to other relevant services (Foster et al. 2016; Reupert \& Maybery 2014) for example, Family Support Services or Carer Support Services. Parents also benefit from support 
in developing and pursuing realistic goals, to take successful steps and achieve their vision for the future. Support includes emotional support and empathy with regard to parenting needs and family relationships (Bartlett et al. 2006; Foster et al. 2016). All parents benefit from support, particularly those whose current functioning may be compromised by illness. While a clinician may focus on routine clinical recommendations, a parent may be focused on meeting practical family needs, which may conflict with the parent's ability to participate in or benefit from treatment. Alignment of parenting and treatment goals can help improve parents' willingness to engage in mental health and family support service plans, and ability to achieve success. Parents and family members may also benefit from advocacy (Foster et al. 2016) in securing communitybased resources, identification of appropriate peer support groups, and/or assistance navigating the appropriate service system.

\section{Educate}

Evidence-based family psychoeducation is a well-established process in mental health (Ward et al. 2017) and provides a foundation for this component, which includes raising parents' awareness of the impact of parenting on their mental health, and the impacts of parental mental illness on child and family wellbeing (Foster et al. 2012). Empowering parents to understand more about their mental illness, and to take the lead in the process of informing their family, is aligned to the recovery approach (Ward et al. 2017). Parents may request help in talking with their children or partner about their illness (Grant et al. 2018). Parents and their children benefit from accurate, credible information about their disorder, relevant treatment approaches, and potential pathways to recovery. For children, gaining a basic understanding of mental illness and dispelling myths (e.g. that they are to blame for their parent's illness) can be powerful messages 
that alleviate worry and distress and contribute to prevention of intergenerational mental illness (Foster et al. 2012; Grove et al. 2013). Psychoeducation can also encourage children to initiate conversations with parents about their parents' illness (Grove et al. 2015) and may lead to them engaging in peer support programs. Information for parents and family can be provided verbally, in written form (e.g. pamphlets), and through online or web-based, audiovisual (e.g. DVD), or smart-phone applications. Parents can benefit from information about the array of services (e.g. housing, childcare, social services) helpful to their recovery as well as to support optimal family functioning. As Reupert and Maybery (2014) contend, parents may also benefit from knowing the value of developing a care plan for their children, should the parent become unwell again in the future.

\section{CONCLUSION}

The EASE practice framework addresses essential aspects of family-focused practice and sits at the essential end of the continuum of family-focused practices. It is a brief, low intensity intervention that aims to strengthen clinicians' capacity to address key psychosocial needs of parents and to strengthen relational recovery in families where parents have mental illness. The framework is intended for implementation as part of routine clinical practice in adult mental health settings and potentially other contexts such as child welfare and primary health care. From an implementation science perspective (Fixsen et al. 2009), applying the EASE framework in practice requires development of tailored training and resources to support clinical practice, and evaluation of resulting practices. From a research perspective, process and outcome data is needed throughout the implementation process including identification of relevant proximal and distal outcomes for clinicians and parent consumers. 


\section{IMPLICATIONS FOR PRACTICE}

Clinical practice can be enhanced with a clearly articulated brief practice framework which provides nurses and other clinicians with an evidence-informed tool to guide them in essential family-focused practices. The application of these essential practices could make practice more effective, and therefore more rewarding, and support positive parent, child, and family outcomes. Practice which meets consumers' family-related needs can improve their understanding of their situation, their satisfaction with service provision, and self-efficacy. A succinct and pragmatic framework such as EASE can facilitate FFP and fit seamlessly into everyday practice, making work easier. Following education in application of the EASE framework in practice, these impacts could be documented, monitored and sustained. 


\section{REFERENCES}

Bartlett, R., Herrick, C.A. \& Greninger, L. (2006). Using a system of care framework for the mental health treatment of children and adolescents. The Journal for Nurse Practitioners, 2, 593598.

Biebel, K., Nicholson, J. \& Woolsey, K. (2014). Implementing an intervention for parents withmental illnesses and their families: Building workforce capacity. Psychiatric Rehabilitation Journal, 37, 209-215, doi:10.1037/prj0000046.

Campbell, L., Hanlon, M-C., Poon, A.W.C., et al. (2012). The experiences of Australian parents with psychosis: The second Australian national survey of psychosis. Australian \& New Zealand Journal of Psychiatry, 46, 890- 900.

Connolly, M. (2007). Practice Frameworks: Conceptual Maps to Guide Interventions in Child Welfare. The British Journal of Social Work, 37, 825-837.

Dalton, J.M. (2003). Development and testing of the theory of collaborative decision-making in nursing practice for triads. Journal of Advanced Nursing, 41, 22-33.

Emerging Minds (2016). Let's Talk About Children: A Guide for Professionals.

Falkov, A. (2015). Parental psychiatric disorder: Translating The Family Model into practice change. In A. Reupert, D. Mayberry, J. Nicholson, M. Gopfert \& M. Seeman (Eds), Parental psychiatric disorder: Distressed parents and their children. 3rd Edition (pp. 227-287).

Cambridge: Cambridge University Press.

Fixsen, D., Blase, K. A., Naoom, S. F. \& Wallace, F. (2009). Core implementation components. Research on Social Work Practice, 19, 531-540.

Fixsen, D. L., Naoom, S. F., Blase, K. A., Friedman, R. M. \& Wallace, F. (2005).

Implementation research: A synthesis of the literature. Tampa, FL: University of South Florida. 
Available online at http://nirn.fmhi.usf.edu/resources/publications/Monograph/

Foster, K.P., Hills, D. \& Foster, K.N. (2017). Addressing the support needs of families when a parent is hospitalised with mental illness: A narrative literature review. International Journal of Mental Health Nursing, doi: 10.1111/inm.12385

Foster, K. \& Isobel, S. (2017). Towards relational recovery: nurses' practices with consumers and families with dependent children in mental health inpatient units. International Journal of Mental Health Nursing, doi: 10.1111/inm.12359

Foster, K., Maybery, D., Reupert, A., et al. (2016). Family focused practice in mental health care: an integrative review. Child \& Youth Services, 37, 129-155.

Foster, K., O’Brien, L. \& Korhonen, T. (2012). Developing resilient children and families where parents have mental illness: a family-focused approach. International Journal of Mental Health Nursing, 21, 3-11.

Goodyear, M., Hill, T.L., Allchin, B., et al. (2015). Standards of practice for the adult mental health workforce: meeting the needs of families where a parent has a mental illness. International Journal of Mental Health Nursing, 24, 169-180.

Goodyear, M., Maybery, D., Reupert, A., et al. (2017). Thinking families: A study of the characteristics of the workforce that delivers family-focussed practice. International Journal of Mental Health Nursing, 26, 238-248.

Grant, A., Goodyear, M., Maybery, D. \& Reupert, A (2016). Differences between Irish and Australian psychiatric nurses' family focused practice in adult mental health services. Archives of Psychiatric Nursing, 30, 132-137. 
Grant, A., Lagdon, S., Devaney, J., et al. (2018). A Study of Health and Social Care

Professionals' Family Focused Practice with Parents who have Mental Illness, their Children and Families in Northern Ireland. Final Report. Belfast: Queen's University Belfast.

Grant, A. \& Reupert, A. (2016). The impact of organizational factors and government policy on psychiatric nurses' family-focused practice with parents who have mental illness, their dependent children, and families in Ireland. Journal of Family Nursing, 22, 199-223.

Grove, C., Reupert, A. \& Maybery, D. (2013). Gaining knowledge about parental mental illness: how does it empower children? Child and Family Social Work, 20, 377 - 386.

Grove, C., Melrose, H., Reupert, A., Maybery, D. \& Morgan, B. (2015). When your parent has a mental illness: children's experience of a psycho-educational intervention. Advances in Mental Health, 13, 127-138.

Hine, R. H., Maybery, D. J. \& Goodyear, M. J. (2018). Identity in recovery for mothers with a mental illness: A literature review. Psychiatric Rehabilitation Journal, 41, 16-28, http://dx.doi.org/10.1037/prj0000215

Korhonen, T., Vehviläinen-Julkunen, K. \& Pietilä, A. M. (2010). Do nurses support the patient in his or her role as a parent in adult psychiatry?: A survey of mental health nurses in Finland. Archives of Psychiatric Nursing, 24, 155-167.

Isobel, S., Foster, K., Edwards, C. (2015). Developing Family Rooms in inpatient mental health units: an exploratory descriptive study. BMC Health Services Research, 15, 238, doi 10.1186/s12913-015-0914-0.

Landeweer, E., Molewijk, B., Hem, M.H. \& Pedersen, R. (2017). Worlds apart? A scoping review addressing different stakeholder perspectives on barriers to family involvement in the 
care for persons with severe mental illness. BMC Health Services Research 17. 349.

doi:10.1186/s12913-017-2213-4

Leamy, M., Bird, V., Le Boutillier, C., Williams, J. \& Slade, M. (2011). Conceptual framework

for personal recovery in mental health: systematic review and narrative synthesis. The British Journal of Psychiatry, 199, 445-452.

Marston, N., Stavnes, K., Van Loon, L., et al. (2016). A content analysis of Intervention Key Elements and Assessments (IKEA): What's in the black box in the interventions directed to families where a parent has a mental illness? Child \& Youth Services, 37, 112-128.

Maybery, D., Foster, K., Goodyear, M., et al . (2015). How can we make the psychiatric workforce more family-focused? In A. Reupert, D. Maybery, J. Nicholson, \& M. Gopfert (Eds). Parental Psychiatric Disorder: Distressed Parents and their Families. 3rd Edition (pp. 301-311). Cambridge: Cambridge University Press.

Maybery, D., Goodyear, M., O’Hanlon, B., Cuff, R. \& Reupert, A. (2014). Profession Differences in Family Focused Practice in the Adult Mental Health System. Family Process, 53, 608-617.

Maybery, D., Goodyear, M., Reupert, A. \& Grant, A. (2016). Worker, workplace or families: What influences family focused practices in adult mental health? Journal of Psychiatric and Mental Health Nursing, 23, 163-171.

Maybery, D. J., Reupert, A. E., Patrick, K., Goodyear, M. \& Crase, L. (2009). Prevalence of parental mental illness inAustralian families. Psychiatric Bulletin, 33, 22-26.

Michie, S., Fixsen, D., Grimshaw, J. M. \& Eccles, M. P. (2009). Specifying and reporting complex behaviour change interventions: the need for a scientific method. Implementation Science, 4, doi:10.1186/1748-5908-4-40 
Montgomery, P., Mossey, S., Bailey, P. \& Forchuk, C. (2011). Mothers with serious mental illness: Their experience of "hitting bottom". ISRN Nursing, 708318. doi: 10.5402/2011/708318 Naughton, M., Maybery, D. \& Goodyear, M. (2017). Prevalence of mental illness within families in a regional child-focussed mental health service. International Journal of Mental Health Nursing, doi10.1111/inm.12386

Nicholson, J., Albert, K., Gershenson, B., Williams, V. \& Biebel, K. (2016). Family Options for parents with mental illness: Mothers' well-being, functioning, and supports and resources at twelve months. American Journal of Psychiatric Rehabilitation, 19, 353-369. DOI: 10.1080/15487768.2016.1231639.

Nicholson, J., Reupert A., Grant A. et al. (2015). The policy context and change for families living with parental mental illness. In A. Reupert, D. Maybery, J. Nicholson, M. Gopfert, \& M. Seeman (Eds.), Parental psychiatric disorder: Distressed parents and their families 3rd Edition (pp. 354-365). Cambridge: Cambridge University Press.

Nicholson, J. with Wolf, T., Wilder, C. \& Biebel, K. (2014). Creating options for family recovery. Marlborough, MA: Employment Options, Inc.

Osher, T.W. \& Osher, D.M. (2002). The paradigm shift to true collaboration with families. Journal of Child \& Family Studies, 11, 47-60.

Parrott, L., Jacobs, G. \& Roberts, D. (2008). Stress and resilience factors in parents with mental health problems and their children (pp. 1-15): Social Care Institute for Excellence.

Price-Robertson, R., Obradovic, A. \& Morgan, B. (2016). Relational recovery: beyond individualism in the recovery approach. Advances in Mental Health, 15, 108-120.

Rampou, A. M., Havenga, Y. \& Madumo, Y. (2015). Parenting experiences of mothers living with a chronic mental illness. Health SA Gesondheid, 20, 118-127. 
Rasic, D., Hajek, T., Alda, M. \& Uher, R. (2014). Risk of mental illness in offspring of parents with schizophrenia,bipolar disorder, and major depressive disorder: A meta-analysis of family high-risk studies. Schizophrenia Bulletin, 40, 28-38.

Reupert, A. \& Maybery, D. (2014). Practitioners' experiences of working with families with complex needs. Journal of Psychiatric and Mental Health Nursing, 21, 642-651.

Reupert, A., Maybery, D., Cox, M. \& Stokes, E.S. (2015). Place of family in recovery models for those with a mental illness. International Journal of Mental Health Nursing, 24, 495-506.

Solantaus, T., Toikka, S., Alasuutari, M., et al. (2009). Safety, feasibility and family experiences of preventive interventions for children and families with parental depression. The International Journal of Mental Health Promotion, 11, 15-24.

Tew, J., Ramon, S., Slade, M., Bird, V., Melton, J. \& Le Boutillier, C. (2012). Social factors and recovery from mental health difficulties: a review of the evidence. The British Journal of Social Work, 42, 443-460.

Thurston, I. (2003). Developing the therapeutic alliance in acute mental health care. Psychoanalytic Psychotherapy, 17, 190-205.

Tungpunkom, P., Maybery, D., Reupert, A., Kowalenko, N. \& Foster K (2017). Mental health professionals' family-focused practice with families with dependent children: a survey study. BMC Health Services Research, 17, 818, doi: 10.1186/s12913-017-2761-7

Umberson, D. \& Montez, J.K. (2010). Social relationships and health: a flashpoint for social policy. Journal of Health and Social Behavior, 51, S54-66.

Van der Ende, P.C., Van Busschbach, J.T., Nicholson, J., Korevaar, E.L. \& Van Weeghel, J. (2016). Strategies for parenting by mothers and fathers with a mental illness. Journal of Psychiatric and Mental Health Nursing, 23, 86-97. 
Ward, B., Reupert, A., McCormick, F., Waller, S. \& Kidd, S. (2017). Family-focused practice within a recovery framework: practitioners' qualitative perspectives. BMC Health Services Research, 17, 234, doi 10.1186/s12913-017-2146-y

Weimand, B.M., Hall-Lord, M.L., Sällström, C. \& Hedelin, B. (2013a). Life-sharing experiences of relatives of persons with severe mental illness - a phenomenographic study. Scandinavian Journal of Caring Science, 27, 99-107.

Weimand, B.M., Hedelin, B., Hall-Lord, M.L.\& Sällström, C. (2011). Left Alone with Straining but Inescapable Responsibilities: Relatives' Experiences with Mental Health Services. Issues in Mental Health Nursing, 32, 703-710.

Weimand, B.M., Sällström, C., Hall-Lord, M.L. \& Hedelin. B. (2013b). Nurses’ dilemmas concerning support of relatives in mental health care. Nursing Ethics, 20, 285-299.

Young, M.E. \& Fristad, M.A. (2007). Evidence based treatments for bipolar disorder in children and adolescents. Journal of Contemporary Psychotherapy, 37, 157-164.

Zugai, J.S., Stein-Parbury, J. \& Roche, M. (2015). Therapeutic alliance in mental health nursing: An evolutionary concept analysis. Issues in Mental Health Nursing, 36, 249-257. 
TABLE 1: EASE Framework with Practice Guidelines and Examples

\begin{tabular}{|c|c|c|}
\hline $\begin{array}{c}\text { EASE Framework } \\
\text { Element }\end{array}$ & Practice Guidelines & Practice Examples \\
\hline $\begin{array}{l}\text { Engage: the process } \\
\text { of approaching the } \\
\text { person, building } \\
\text { positive rapport, and } \\
\text { strengthening a } \\
\text { relationship with the } \\
\text { person }\end{array}$ & $\begin{array}{l}\text { Identify the person's parenting } \\
\text { status, whether they have a } \\
\text { partner, and other significant } \\
\text { family relationships. } \\
\text { Briefly explore basic details } \\
\text { about their children (e.g., age, } \\
\text { where living, school, who } \\
\text { provides care, frequency of } \\
\text { contact, nature of relationship). } \\
\text { Acknowledge that talking about } \\
\text { mental illness with children and } \\
\text { family may be challenging (or, } \\
\text { alternatively, quite rewarding). }\end{array}$ & $\begin{array}{l}\text { "Could you tell me a little about your } \\
\text { family?" "Do you have children?" } \\
\text { "Do you have a partner?" } \\
\text { "How old are your children?" } \\
\text { "Where do they live?" "Are they in } \\
\text { school?" etc. } \\
\text { "It sounds like you're worried that } \\
\text { managing your illness/hospitalization } \\
\text { is stressful for your children and your } \\
\text { partner. They may also be relieved } \\
\text { that you are safe, managing your } \\
\text { illness and getting help. We can talk } \\
\text { about ways to help them and you } \\
\text { cope." }\end{array}$ \\
\hline $\begin{array}{l}\text { Assess: the process } \\
\text { of obtaining } \\
\text { information about } \\
\text { the person's } \\
\text { responsibilities, } \\
\text { goals and needs as a } \\
\text { parent and a partner, } \\
\text { along with some } \\
\text { understanding of } \\
\text { their life context and } \\
\text { family needs and } \\
\text { concerns. }\end{array}$ & $\begin{array}{l}\text { Explore parenting/family roles } \\
\text { and responsibilities, and what } \\
\text { the person has talked about in } \\
\text { terms of their illness with their } \\
\text { family. } \\
\text { Ask about person's partner; the } \\
\text { ways they communicate; and } \\
\text { what their partner's main } \\
\text { concerns might be in relation to } \\
\text { their mental health. }\end{array}$ & $\begin{array}{l}\text { "Have you talked with your child/ren } \\
\text { about your mental health?" } \\
\text { "You have [\#] children, what do you } \\
\text { think [child] would say if s/he was } \\
\text { here with you"? } \\
\text { "What do you think your children's } \\
\text { concerns are in relation to your } \\
\text { mental health?" } \\
\text { "Have you talked with your partner } \\
\text { about your mental health?" "What do } \\
\text { you think your partner worries } \\
\text { about?" "Does your partner have } \\
\text { ideas about solution(s)?" } \\
\text { "What would be the most helpful for } \\
\text { talking about your mental health with } \\
\text { your child/partner?" }\end{array}$ \\
\hline
\end{tabular}




\begin{tabular}{|c|c|c|}
\hline $\begin{array}{c}\text { EASE Framework } \\
\text { Element }\end{array}$ & Practice Guidelines & Practice Examples \\
\hline $\begin{array}{l}\text { Support: the process } \\
\text { of supporting the } \\
\text { parent, helping the } \\
\text { parent to support } \\
\text { children/partner/ } \\
\text { other family } \\
\text { members, accessing } \\
\text { professional services } \\
\text { and building natural } \\
\text { supports. }\end{array}$ & $\begin{array}{l}\text { Ask about immediate unmet } \\
\text { needs in relation to person's } \\
\text { children \& family } \\
\text { Ask about informal or natural } \\
\text { and professional supports for the } \\
\text { parent and family members. } \\
\text { Suggest available resources and } \\
\text { make referrals. }\end{array}$ & $\begin{array}{l}\text { "If there's one thing we could help } \\
\text { you (your partner/child) with today, } \\
\text { what would it be?" } \\
\text { "Who do you (your partner) turn to } \\
\text { when you need help?" "Who depends } \\
\text { on you? For what kinds of things?" } \\
\text { "It sounds like you would like more } \\
\text { support with parenting when you're } \\
\text { unwell. Here's some contact } \\
\text { information for support services (eg. } \\
\text { Family Support/Carer Support/Peer } \\
\text { Support) that could be helpful". }\end{array}$ \\
\hline $\begin{array}{l}\text { Educate: the process } \\
\text { of providing } \\
\text { information and } \\
\text { access to } \\
\text { psychoeducation } \\
\text { resources to help the } \\
\text { individual \& their } \\
\text { partner/child } \\
\text { understand his/her } \\
\text { illness and recovery } \\
\text { and support the } \\
\text { development of } \\
\text { children's resilience } \\
\text { to mitigate the } \\
\text { potential impact of } \\
\text { their parent's mental } \\
\text { illness on their lives. }\end{array}$ & $\begin{array}{l}\text { Identify the main information } \\
\text { needs at present for the parent } \\
\text { (partner/child) } \\
\text { Provide verbal, written and/or } \\
\text { online psychoeducation } \\
\text { resources for person, their } \\
\text { child/ren, and partner, as } \\
\text { relevant. } \\
\text { Leave parent and/or family } \\
\text { member with a verbal list of } \\
\text { things that are going well, and } \\
\text { the strengths and resources they } \\
\text { have in place. } \\
\text { Remind the parent that change } \\
\text { happens in small steps and leave } \\
\text { them with hope for the future. }\end{array}$ & $\begin{array}{l}\text { "If there's one helpful thing you'd } \\
\text { take away from our conversation, } \\
\text { what would it be?" } \\
\text { (If patient/parent can't think of } \\
\text { anything, e.g. "Could you give me } \\
\text { some clues?") } \\
\text { "There have been lots of resources } \\
\text { developed for parents and families } \\
\text { living with mental illness. Here's } \\
\text { some information } \\
\text { (verbal/written/online) that may be } \\
\text { helpful for you/your partner/child". } \\
\text { "You've told me about some ways in } \\
\text { which you are quite successful at } \\
\text {............" } \\
\text { "You've made real progress } \\
\text { in............" } \\
\text { "Change happens in small steps. } \\
\text { What would the next step look like?" } \\
\text { "How will you know when you have } \\
\text { taken that next step?" "How can we } \\
\text { help?" }\end{array}$ \\
\hline
\end{tabular}




\section{CASE EXAMPLE - USING EASE IN AN INPATIENT SETTING}

Tony and Mary have been together for 7 years and recently had their first child. Mary also has a 9 year old boy (Danny) from a previous relationship. After years of IVF treatment, Mary gave birth to a baby girl (Hayley) 4 months ago. While excited, Tony, who had a history of major depression but had not had any major episodes during their relationship, continued to work long hours. Mary had stopped work to care for the baby. In the first months since Hayley was born Tony has become more and more engrossed in his work, and talked incessantly with Mary about being watched by others. Mary noticed Tony withdrawing from Hayley, rarely responding to her cues, nor helping Mary parent the children. Mary and Tony's relationship deteriorated further after Tony was sacked from his job for sending messages to his boss' wife, believing they could run away together. Tony agreed to go to the emergency department with Mary and was admitted to the mental health inpatient unit as a voluntary patient.

James, a registered nurse, had admitted Tony to the unit and asked him as part of the initial assessment about his family, so knew he had a partner and two children. James saw that Mary visited Tony regularly with Hayley and Mike, and they went to the Family Room in the unit. Tony had been commenced on oral antipsychotics, with significant side effects. Mary kept in regular communication with staff about Tony's treatment plans, and it was decided that Tony would be transferred shortly to a step-down facility for monitoring with his medication. James approached Tony a few days before his transfer, and chatted with him about his children and family. James acknowledged that Tony's admission might be challenging for him, Mary and the children, and asked Tony what he thought Mary's main concerns might be in relation to his illness and admission. Tony thought Mary was trying to understand his illness as this was the first time he had been really unwell during their relationship. James also asked Tony whether he and/or Mary had talked with Danny about his illness. They had explained to Danny that Tony was unwell but not specifically about his illness as they didn't want to worry him.

James asked Tony if there was one thing he could help with today in relation to his family's needs, what would that be? They agreed that information for Mary about Tony's illness, and some ideas on how to talk with Danny about his illness, would be most helpful. James got two information packs that were kept on the unit and discussed them with Tony - one pack for family/carers, and one for parents with school-aged children. They included psychoeducation material - a 'flip' book with information for parents with mental illness, and on the 'flip' side information and key messages for their children that parents and children could talk about together. There were brochures for Mary on depression and psychosis, Carer Support Services, and a local Peer Support Group for children of parents with mental illness, and fridge magnets for a website which had information and videos for children and parents about mental illness. James encouraged Tony to discuss the packs with Mary when she visited and acknowledged Tony's and Mary's strength and commitment to each other and to their children. James later 
documented their discussion and his actions in Tony's case notes, and referred Tony and Mary to the local Family Support Services team for when Tony moved to the step-down unit. 


\section{CASE EXAMPLE - USING EASE IN A COMMUNITY SETTING}

Helen, aged 20, is the single mother of Jonah, a baby boy aged 8 months. Jonah was born four weeks prematurely and has been quite unsettled since birth. Helen and Jonah live with Helen's father, Tom, a widower since Helen's mother died a year ago. Helen's father suspects that Helen suffers from post-partum depression, and has encouraged her to talk with her GP, which she has refused. Helen is afraid that child protection services will take her son away, particularly as she was treated at an out-patient clinic for anorexia nervosa when she was 18. Helen had however fully recovered from what she called "her youth problems" after receiving treatment for a year.

A couple of months ago, Helen re-connected with Jonah's father; Chris and they agreed to cooperate together on Jonah's upbringing. Chris is ten years older than Helen; he owns his own apartment and has a secure job. Even though Helen realizes she may have post-partum depression, she is afraid to talk with Chris about it. After Helen's mood further deteriorates, her father has gained her permission to speak with the community mental health team (CMHT) for advice. Helen's father Tom rang the CMHT and spoke with a mental health nurse and asked if Helen could get some help with establishing a wider social network for young mothers and if she could be referred to the CMHT. Tom also indicated he would like to discuss his own concerns in supporting Helen and Jonah.

The following week, an experienced registered nurse, Patricia, visited Helen at home. Patricia asked Helen how she was doing, and talked with her about usual challenges for a first time mother. Helen said she suffered from lack of sleep, and that she worried a lot about the baby. Patricia asked who Helen could ask for help and assistance. Helen explained that she really missed her mother who used to be an important support for her, and that her father was really not able to help her as she felt like he was interfering. Patricia acknowledged that it must be very hard for Helen not having her mother there as support. They also talked about Chris and how he might further support Helen. Helen acknowledged she was a bit worried that she might suffer from post-partum depression.

Patricia asked Helen if she had talked with her father or Chris about her worries and her mental health and whether she thinks either of them might have some worries or questions, or even some ideas about solutions. Helen said she would like to include Chris more, but she's also afraid he might withdraw if he thinks that she's unwell. On the other hand, her father might need some explanation and support about parenting young babies; she has noticed that he worries a lot about the baby, which is also stressful for her. Patricia says she understands Helen's concerns and affirms that most parents can find parenting stressful, particularly if the baby is unsettled, and that parenting support can be beneficial in helping them cope. She gives Helen some booklets on parenting tips for young babies and suggests Tom might also like to read them. Patricia offers to meet with Helen and Tom at a convenient time to talk about any concerns he might have and how he can best support Helen and Jonah. Patricia observed Helen cuddling 
Jonah throughout the visit and reassured Helen she was being responsive and loving. Patricia suggested that Helen might benefit from meeting other young mums and their children in her local community mother-baby group. She also sought Helen's permission to refer her to a psychiatrist within the CMHT to discuss her postpartum symptoms and Helen agreed. Patricia recorded the home visit, her assessment and actions taken when she returned to the CMHT. 


\section{TABLE 1: EASE Framework with Practice Guidelines and Examples}

\begin{tabular}{|c|c|c|}
\hline $\begin{array}{c}\text { EASE Framework } \\
\text { Element }\end{array}$ & Practice Guidelines & Practice Examples \\
\hline $\begin{array}{l}\text { Engage: the process } \\
\text { of approaching the } \\
\text { person, building } \\
\text { positive rapport, and } \\
\text { strengthening a } \\
\text { relationship with the } \\
\text { person }\end{array}$ & $\begin{array}{l}\text { Identify the person's parenting } \\
\text { status, whether they have a } \\
\text { partner, and other significant } \\
\text { family relationships. } \\
\text { Briefly explore basic details } \\
\text { about their children (e.g., age, } \\
\text { where living, school, who } \\
\text { provides care, frequency of } \\
\text { contact, nature of relationship). } \\
\text { Acknowledge that talking about } \\
\text { mental illness with children and } \\
\text { family may be challenging (or, } \\
\text { alternatively, quite rewarding). }\end{array}$ & $\begin{array}{l}\text { "Could you tell me a little about your } \\
\text { family?" "Do you have children?" } \\
\text { "Do you have a partner?" } \\
\text { "How old are your children?" } \\
\text { "Where do they live?" "Are they in } \\
\text { school?" etc. } \\
\text { "It sounds like you're worried that } \\
\text { managing your illness/hospitalization } \\
\text { is stressful for your children and your } \\
\text { partner. They may also be relieved } \\
\text { that you are safe, managing your } \\
\text { illness and getting help. We can talk } \\
\text { about ways to help them and you } \\
\text { cope." }\end{array}$ \\
\hline $\begin{array}{l}\text { Assess: the process } \\
\text { of obtaining } \\
\text { information about } \\
\text { the person's } \\
\text { responsibilities, } \\
\text { goals and needs as a } \\
\text { parent and a partner, } \\
\text { along with some } \\
\text { understanding of } \\
\text { their life context and } \\
\text { family needs and } \\
\text { concerns. }\end{array}$ & $\begin{array}{l}\text { Explore parenting/family roles } \\
\text { and responsibilities, and what } \\
\text { the person has talked about in } \\
\text { terms of their illness with their } \\
\text { family. } \\
\text { Ask about person's partner; the } \\
\text { ways they communicate; and } \\
\text { what their partner's main } \\
\text { concerns might be in relation to } \\
\text { their mental health. }\end{array}$ & $\begin{array}{l}\text { "Have you talked with your child/ren } \\
\text { about your mental health?" } \\
\text { "You have [\#] children, what do you } \\
\text { think [child] would say if s/he was } \\
\text { here with you"? } \\
\text { "What do you think your children's } \\
\text { concerns are in relation to your } \\
\text { mental health?" } \\
\text { "Have you talked with your partner } \\
\text { about your mental health?" "What do } \\
\text { you think your partner worries } \\
\text { about?" "Does your partner have } \\
\text { ideas about solution(s)?" } \\
\text { "What would be the most helpful for } \\
\text { talking about your mental health with } \\
\text { your child/partner?" }\end{array}$ \\
\hline
\end{tabular}




\section{Practice Examples}

"If there's one thing we could help you (your partner/child) with today, what would it be?"

"Who do you (your partner) turn to when you need help?" "Who depends on you? For what kinds of things?"

"It sounds like you would like more support with parenting when you're unwell. Here's some contact information for support services (eg. Family Support/Carer Support/Peer Support) that could be helpful".

"If there's one helpful thing you'd take away from our conversation, what would it be?"

(If patient/parent can't think of anything, e.g. "Could you give me some clues?")

Provide verbal, written and/or online psychoeducation resources for person, their child/ren, and partner, as relevant.

Leave parent and/or family member with a verbal list of things that are going well, and the strengths and resources they have in place.

Remind the parent that change happens in small steps and leave them with hope for the future.
"There have been lots of resources developed for parents and families living with mental illness. Here's some information (verbal/written/online) that may be helpful for you/your partner/child".

"You've told me about some ways in which you are quite successful at

"You've made real progress in............"

"Change happens in small steps. What would the next step look like?" "How will you know when you have taken that next step?" "How can we help?" 